\title{
Precision Permittivity Measurement for Low-Loss Thin Planar Materials Using Large Coaxial Probe from 1 to $400 \mathrm{MHz}$
}

\author{
Kok Yeow You *(D) and Man Seng Sim $\mathbb{D}$ \\ School of Electrical Engineering, Faculty of Engineering, Universiti Teknologi Malaysia, \\ 81310 Skudai, Johor, Malaysia; mssim1993@graduate.utm.my \\ * Correspondence: kyyou@fke.utm.my; Tel.: +60-17-9529948
}

Received: 12 October 2018; Accepted: 27 November 2018; Published: 4 December 2018

check for updates

\begin{abstract}
This paper focuses on the non-destructive dielectric measurement for low-loss planar materials with a thickness of less than $3 \mathrm{~mm}$ using a large coaxial probe with an outer diameter of $48 \mathrm{~mm}$. The aperture probe calibration procedure required only to make a measurement of the half-space air and three offset shorts. The reflection coefficient for the thin material is measured using a Keysight E5071C network analyzer from $0.3 \mathrm{MHz}$ to $650 \mathrm{MHz}$ and then converted to a relative dielectric constant, $\varepsilon_{r}$ and tangent loss, $\tan \delta$ via closed form capacitance model and lift-off calibration process. Average measurement error of dielectric constant, $\Delta \varepsilon_{r}$ is less than $6 \%$ from $1 \mathrm{MHz}$ to $400 \mathrm{MHz}$ and the resolution of loss tangent, $\tan \delta$ measurement is capable of achieving $10^{-3}$.
\end{abstract}

Keywords: large coaxial probe; thin planar materials; low-loss materials; relative permittivity; reflection coefficient; calibration

\section{Introduction}

Sensitivity, sustainability, and simplicity in operations are important requirements for sensing devices in large-scale material processing industries. To reduce the uncertainty of the measurements, the sensors should have a large sensing area, a high concentration of sensing field, and high sensitivity to the slight changes in material under test (MUT). The operating frequency of the permittivity, $\varepsilon_{r}$ measurements in most of the material processing industries are up to a few hundred $\mathrm{MHz}$ [1-3].

The open-ended coaxial probe technique is a simple, broadband, and non-destructive way to measure the relative permittivity, $\varepsilon_{r}$ of a material. Coaxial probes have been commercialized and used commonly since 1990 [4]. Recently, several probes have produced by manufacturers such as SPEAG Inc. [5], KEYCOM [6], and APREL Inc. [7]. However, coaxial probes (N-type's or SMA's diameter size) are less sensitive to small changes in the MUT especially for thin and low-loss materials in permittivity, $\varepsilon_{r}$ measurement at $\mathrm{MHz}$ frequency. This causes the measurement results for low-loss materials at low frequencies to be highly scattered and less precise [8]. In fact, most coaxial probes are only suitable for half-space infinite lossy material with $\varepsilon_{r}{ }^{\prime}>5$ and $\tan \delta>0.05$ [4-11].

In this study, a large open-ended coaxial probe was designed to overcome those issues, which is capable of measuring the $\varepsilon_{r}$ of low-loss materials having thickness of $1 \mathrm{~mm}$ precisely from 1 to $400 \mathrm{MHz}$. The designed large probe is heavy whereby it is capable of supplying stable reflection measurements. Additionally, it is sensitive to measurements at low frequencies due to its large size. Furthermore, large probe aperture (sensing area) can reduce the uncertainty of measurement, which mostly caused by the inequality of composite distribution in MUT, especially for inhomogeneous MUTs. The probe design of the probe and its performance were analyzed in detail. An explicit formulation for the prediction of $\varepsilon_{r}$, which does not involve numerical inversion routines (iterative method) as in 
Refs. [8-11] is used. Since this study is focused on low frequencies measurement (up to $400 \mathrm{MHz}$ ), thus, a simple closed-form capacitance model [12-18] is implemented to predict the dielectric properties of MUT based on the measured reflection coefficient at probe aperture. The differences in this study compared with previous works are summarized in Table 1. In Refs. [8-11], the iterative methods (inverse methods) used to estimate the permittivity, $\varepsilon_{r}$ of lossy MUT in which the predicted values of $\varepsilon_{r}$ are obtained by minimizing the difference between the measured aperture reflection coefficient and the theoretical calculations. Those iterative methods are complicated solutions and less suitable for real-time $\varepsilon_{r}$ estimation.

Table 1. Comparative study of large probe.

\begin{tabular}{|c|c|c|c|c|c|c|c|c|}
\hline Ref. & $\begin{array}{c}\text { Probe Size } \\
(\mathrm{cm})\end{array}$ & $\underset{(\mathrm{MHz})}{f}$ & $\begin{array}{c}\text { Transition } \\
\text { Section }\end{array}$ & $\begin{array}{l}\text { Sample } \\
\text { Contact }\end{array}$ & $\begin{array}{c}\text { Sample } \\
\text { Size/Shape }\end{array}$ & $\begin{array}{l}\text { Calibration } \\
\text { Standards }\end{array}$ & $\begin{array}{l}\text { Measured } \\
\varepsilon_{r}^{\prime} \text { Range }\end{array}$ & $\begin{array}{l}\text { Inverse } \\
\text { Method }\end{array}$ \\
\hline$[8]$ & $\begin{array}{c}2 a=1.00 \\
2 b=3.25 \\
L=5.00\end{array}$ & $100-900$ & without & $\begin{array}{l}\text { Aperture } \\
\text { probe }\end{array}$ & $\begin{array}{l}\text { Half-space } \\
\text { infinite }\end{array}$ & $\begin{array}{l}\text { Air, short, } \mathrm{NaCl} \\
\text { solution. }\end{array}$ & $\sim 5-80$ & Iterative \\
\hline [9] & $\begin{array}{c}2 a=1.00 \\
2 b=3.25 \\
L=5.00\end{array}$ & $\begin{array}{l}1-10 \text { or } \\
10-3000\end{array}$ & without & $\begin{array}{l}\text { Aperture } \\
\text { probe }\end{array}$ & $\begin{array}{l}\text { Half-space } \\
\text { infinite }\end{array}$ & $\begin{array}{l}\text { Short cavity orAir, } \\
\text { short, short cavity }\end{array}$ & $\begin{array}{l}\sim 30-80 \\
\text { (Lossy) }\end{array}$ & Iterative \\
\hline [10] & $\begin{array}{l}2 a=1.18 \\
2 b=4.00 \\
L \approx 13.0\end{array}$ & $200-1500$ & with & $\begin{array}{l}\text { Aperture } \\
\text { probe }\end{array}$ & $\begin{array}{l}\text { Half-space } \\
\text { infinite }\end{array}$ & $\begin{array}{l}\text { Air, copper plate, } \\
\text { Teflon plate. }\end{array}$ & $\begin{array}{c}\sim 2-35 \\
\text { (Lossy) }\end{array}$ & Iterative \\
\hline [11] & $\begin{array}{l}2 a=4.50 \\
2 b=10.3 \\
L \approx 41.0\end{array}$ & 50-1000 & with & $\begin{array}{l}\text { Filled in } \\
\text { coaxial line }\end{array}$ & Toroid-shaped & $\begin{array}{l}3 \text { positions } \\
\text { short-circuit along } \\
\text { the coaxial line }\end{array}$ & $\begin{array}{c}\sim 7-80 \\
\text { (Lossy) }\end{array}$ & Iterative \\
\hline [12] & $\begin{array}{l}2 a=2.35 \\
2 b=5.4 \\
L \approx 4.4\end{array}$ & $100-250$ & with & $\begin{array}{l}\text { Filled in } \\
\text { coaxial line }\end{array}$ & Toroid-shaped & $\begin{array}{l}\text { Based on specified } \\
\text { specimen under test }\end{array}$ & $\begin{array}{c}1-50 \\
\text { (Low lossy) }\end{array}$ & Non-iterative \\
\hline $\begin{array}{l}\text { This } \\
\text { study }\end{array}$ & $\begin{array}{c}2 a=1.50 \\
2 b=4.80 \\
L=15.0\end{array}$ & $1-400$ & with & $\begin{array}{l}\text { Aperture } \\
\text { Probe }\end{array}$ & $\begin{array}{l}\text { Thin planar } \\
\text { backed by } \\
\text { metal plate }\end{array}$ & Air, 3 offset shorts & $\begin{array}{c}1-20 \\
\text { (Lossless) }\end{array}$ & Non-iterative \\
\hline
\end{tabular}

${ }^{*} L$ is the coaxial length of the probe.

Although the probe designs in Refs. [8,9] did not use the transitions section on the boundary between the connector and the coaxial line, the mismatch reflection errors that exist on the boundary can be eliminated after the rigorous aperture calibration is performed. In fact, a high sensitivity measurement can be achieved by a method in which the MUT is filled in a coaxial line as in Refs. [11,12]. However, this measurement method encounters difficulties in the sample preparation stage in which the sample (MUT) must be identified to fully fill in without any air gap between the inner conductor and the outer conductor. Furthermore, it is only suitable for semi-liquid or powder form MUTs.

\section{Large Coaxial Probe Design}

\subsection{Coaxial Probe Formulations}

The earliest coaxial probe formula derivation (during early 1950) [19] concerned the homogeneous case, which an air-filled coaxial line with an infinite conducting flange is radiated into the free space. The aperture normalized admittance, $\widetilde{Y}$ of the probe was expressed in variational integral equations. During that time, the main implementation of open-ended coaxial line is used as an antenna. The open-ended coaxial probe began to be applied as a dielectric probe sensor during early 1980s. The rigorous integral formulation was investigated back by Refs. [20,21]. However, those integrations are difficult to use to solve the inverse problem analytically. Thus, a lot of literature [13-17] formulated the aperture admittance in closed-form capacitance, $C_{o}$ terms in which it is easily used to estimate the relative complex permittivity, $\varepsilon_{r}$ of MUT at low operating frequencies as follows:

$$
\widetilde{Y}=j \omega\left(\varepsilon_{r} C_{o}+C_{f}\right) / Y_{o}
$$


where $Y_{o}$ is the characteristic admittance of coaxial line. In 1986, the modeling of open-ended coaxial probe that is terminated by layered media was studied by Ref. [22]. Subsequently, probe modeling studies which considered multi-layer MUT were rapidly developed during 1990 [23-33].

\subsection{Dimensions and Structure}

The designed coaxial probe as shown in Figure 1a is made of brass, since the material is relatively low cost and has slower surface oxidation process when it is exposed to the moisture in the air. The dimensions of the coaxial probe with outer radius of inner conductor, $a=7.5 \mathrm{~mm}$ and inner radius of outer conductor, $b=24.0 \mathrm{~mm}$, were designed based on the characteristic impedance, $Z_{o}=[60 \times$ $\left.\ln (b / a) / \sqrt{ } \mathcal{E}_{c}\right]=50 \Omega$. The maximum limit of the operating frequency, $f_{\max }$ propagating in the coaxial line of the probe is determined using $\mathrm{TE}_{11}$ cut-off as: $f_{\max }=\left(3 \times 10^{8}\right) /\left[\pi(b+a) \sqrt{ } \varepsilon_{c}\right] \approx 2.1 \mathrm{GHz}$. In fact, the limit of operation frequency of the practice coaxial line is always much lower than the $\mathrm{TE}_{11}$ cutoff frequency based on the quality and precision of machining. The symbol $\varepsilon_{\mathcal{C}}$ (Air: $\varepsilon_{\mathcal{C}}=1$, Teflon: $\varepsilon_{\mathcal{C}}=$ 2.06) represents the relative permittivity of material filling in the coaxial line in between the inner and outer conductor. The total weight of the coaxial probe is $2.6 \mathrm{~kg}$. It has been divided into three sections: (I) N-type connector, which is used to connect the coaxial probe with the network analyzer via cable. (II) Transition section, which is a $50 \mathrm{~mm}$ of air-filled conical taper. The radius $a$ and $b$ of the conductors are increased along the transition length with a constant ratio, $b / a=2.3$. Ratio, $b / a=2.3$ is required to maintain $Z_{o}=50 \Omega$ along the transition length to achieve low return loss and the lowest standing wave ratio (SWR) during the transformation from small to large coaxial line. (III) Large coaxial line section, which is a $100 \mathrm{~mm}$ length of $50 \Omega$ Teflon-filled coaxial line with $b / a=3.3$. The Teflon isolation block is used to prevent the MUT from getting into the coaxial line. In addition, Teflon has high flexural strength, excellent chemical resistance, and high stability over a wide temperature range.

(a)

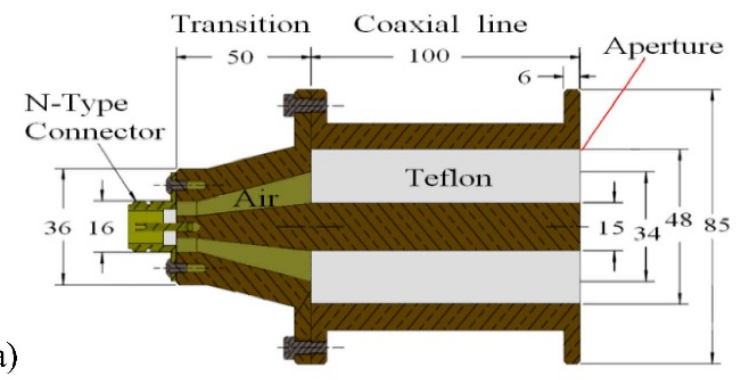

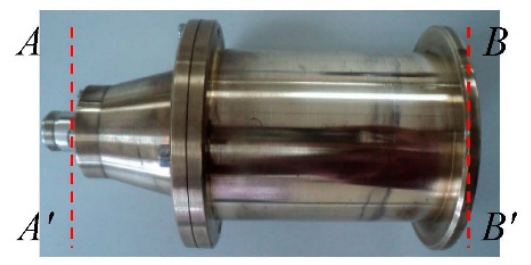

(b)

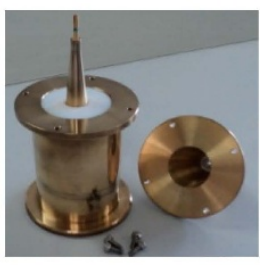

(c)

Figure 1. (a) Cross-sectional side view and dimensions (in $\mathrm{mm}$ ) of the coaxial sensor. (b) Side view of the large coaxial sensor. (c) Internal configuration of the coaxial sensor.

\subsection{Probe Characterization Test}

The complex reflection coefficient, $\Gamma_{A A^{\prime}}=\left|\Gamma_{A A^{\prime}}\right| \exp \left(j \varphi_{A A^{\prime}}\right)$ at plane $\mathrm{AA}^{\prime}$ for four MUTs were measured using Keysight E5071C network analyzer (Keysight Technologies, Santa Rosa, CA, USA) in the frequency ranging from $0.3 \mathrm{MHz}$ to $650 \mathrm{MHz}$ at $25^{\circ} \mathrm{C}$. Calibration was done at the $\mathrm{AA}^{\prime}$ plane, as shown in Figure 2, using Keysight 85032F kit (Keysight Technologies, Santa Rosa, CA, USA). 


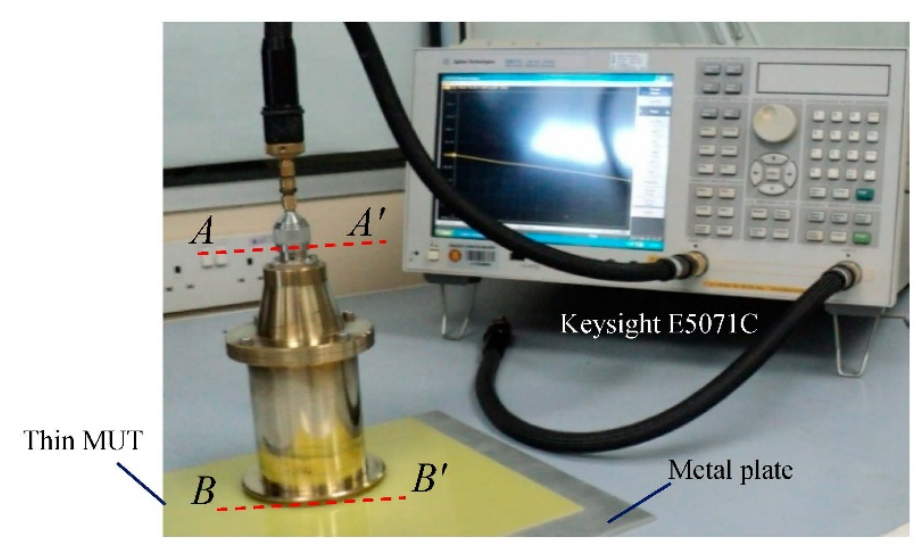

Figure 2. Experimental set-up and measurement.

The sensing distance, $\mathrm{h}$ of the probe is $30 \mathrm{~mm}$, which was estimated based on the distance at which the measured phase shift, $\varphi_{A A^{\prime}}(\mathrm{rad})$ as shown in Figure $3 \mathrm{a}, \mathrm{b}$ starts to become constant when the metallic plate is moved away from the probe aperture in air. Figure 4 shows the time-domain measurements of the coaxial probe, which is operated with minimum windowing and bandpass mode. Clearly, coaxial probe of $15 \mathrm{~cm}$ length is sufficient to avoid the interference between plane- $\mathrm{AA}^{\prime}$ and $-\mathrm{BB}^{\prime}$ for the frequency-domain $\Gamma_{A A^{\prime}}$ measurement.

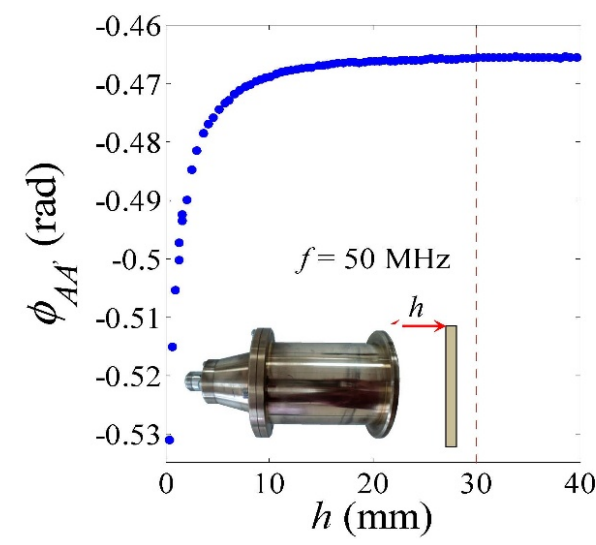

(a)

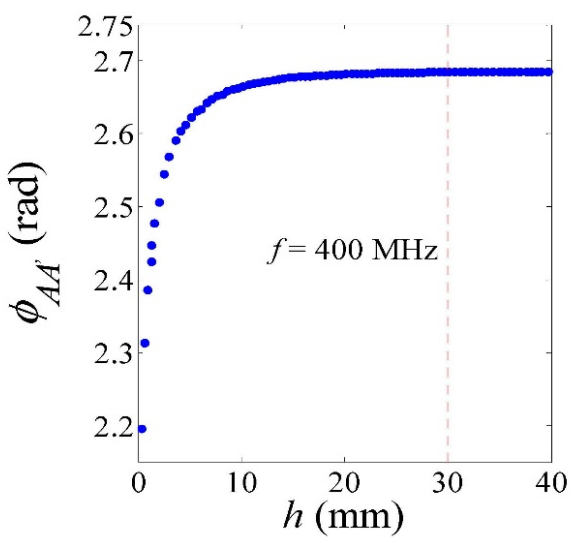

(b)

Figure 3. Variation in phase shift $\varphi_{A A^{\prime}}$ with air thickness, $h$ backed by metal plate at (a) $50 \mathrm{MHz}$ and (b) $400 \mathrm{MHz}$.

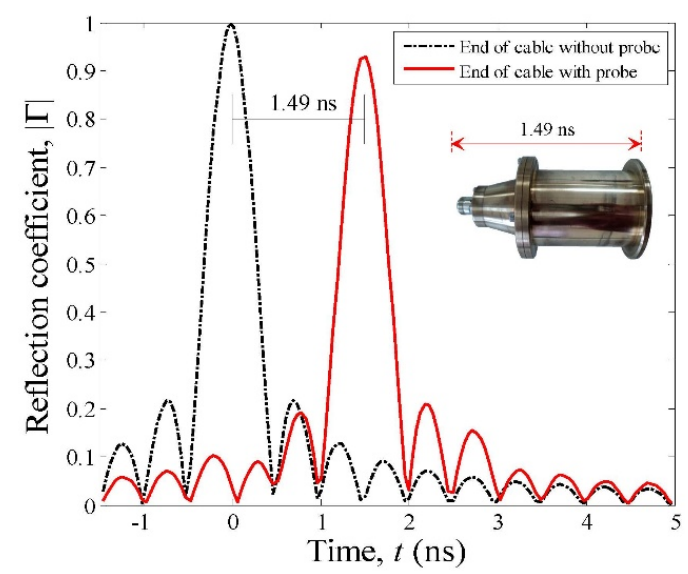

Figure 4. The time-domain response for the end of cable at plane-AA' with and without probe. 


\section{Calibrations}

\subsection{Calibration Formulations}

Before the one-port reflection measurement is conducted, the open-ended coaxial probe is regularly calibrated at the end of the coaxial line (probe aperture) in order to remove the effects of the coaxial line between $\mathrm{AA}^{\prime}$ plane and $\mathrm{BB}^{\prime}$ plane. The relationship between the actual reflection coefficient, $\Gamma_{B B^{\prime}}$ at the probe aperture $\left(\mathrm{BB}^{\prime}\right.$ plane) and measured $\Gamma_{A A^{\prime}}$ can be represented by an error network as shown in Figure 5, and its formulation is given as [34]:

$$
\Gamma_{B B^{\prime}}=\frac{\Gamma_{A A^{\prime}}-e_{11}}{e_{22} \Gamma_{A A^{\prime}}+\left(e_{12} e_{21}-e_{11} e_{22}\right)}
$$

where the $e_{12} e_{21}$ terms in Equation (2) represents the values of tracking error, as well as the $e_{11}$ and $e_{22}$ are the values of the directivity error and the source match error, respectively. These errors are contributed by shifted phase, attenuate loss in the coaxial line $\left(e_{12} e_{21}\right)$, and the radiate fringing effects at the probe aperture $\left(e_{11}\right.$ and $\left.e_{22}\right)$, which are mainly caused by the occurrence of standing waves in the coaxial line.

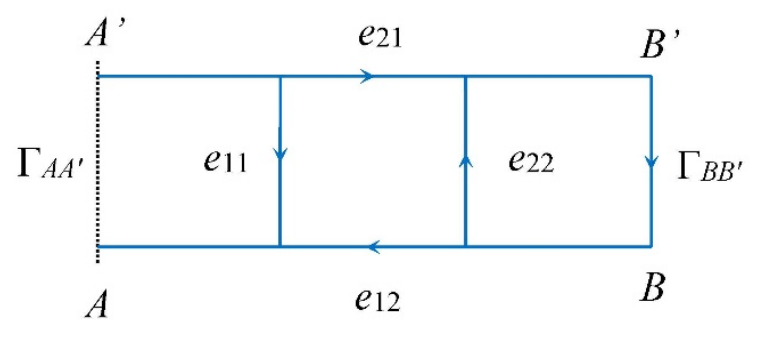

Figure 5. Error network.

For simplicity of calibration process, only air independent calibration standard is considered in the de-embedded process. Thus, the errors of a standing wave and mismatch between connectors are not taken into account in the calibration, and the values of $e_{11}$ and $e_{22}$ are assumed to be zero. Finally, Equation (2) can be reduced as:

$$
\left(e_{12} e_{21}-e_{11} e_{22}\right)=\frac{\Gamma_{A A^{\prime} \_A i r}}{\Gamma_{B B^{\prime} \_A i r}}
$$

where $\Gamma_{A A^{\prime} \_ \text {Air }}$ is the reflection coefficient measurement, for air at plane $\mathrm{AA}^{\prime}$, and $\Gamma_{B B^{\prime}{ }_{-} \text {Air }}$ is the standard value of the air reflection coefficient at plane $\mathrm{BB}^{\prime}$, obtained using the COMSOL simulator. Similarly, for MUT measurement, the Equation (2) can be expressed as:

$$
\left(e_{12} e_{21}-e_{11} e_{22}\right)=\frac{\Gamma_{A A^{\prime} \_M U T}}{\Gamma_{B B^{\prime} \_M U T}}
$$

By combining Equations (3) and (4), the desired actual reflection coefficient, $\Gamma_{B B^{\prime}}{ }_{-} M U T$ of the MUT can be obtained as:

$$
\Gamma_{B B^{\prime} \_M U T}=\Gamma_{A A^{\prime} \_M U T}\left(\frac{\Gamma_{B B^{\prime} \_ \text {Air }}}{\Gamma_{A A^{\prime} \_ \text {Air }}}\right)
$$

where $\Gamma_{A A^{\prime} \_M U T}$ is the reflection coefficient measurement, for MUT at plane $\mathrm{AA}^{\prime}$. Equation (5) can be converted in terms of normalized admittance parameter as given in Equation (12). It should be noted that the errors of $e_{11}$ and $e_{22}$ are implicitly removed by effective permittivity calibration process as described in Section 3.3.

In Ref. [32], the dependence of each capacitance on the MUT thickness, $d$ at probe apperture as shown in Figure 6, is empirically assumed to be exponential as:

$$
C_{1}=\varepsilon_{r 1}^{\prime} C_{o}[1-\exp (-d / M)]
$$




$$
C_{2}=\varepsilon_{r 2}^{\prime} C_{o} \exp (-d / M)
$$

where $M$ is an empirical parameter with the dimensions of length.

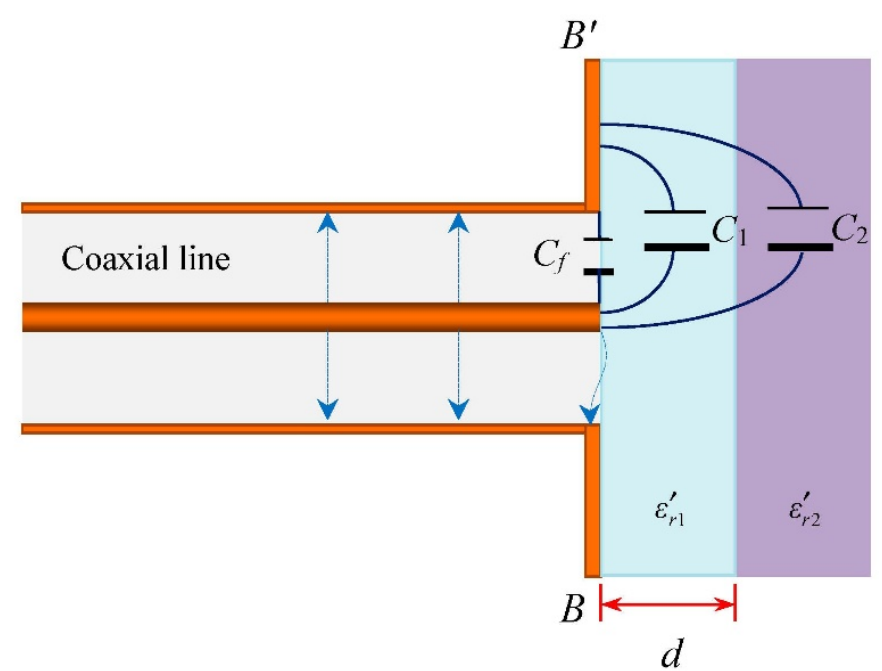

Figure 6. Equivalent parallel capacitance model.

Thus, the total terminal capacitance, $C_{T}$ at $\mathrm{BB}^{\prime}$ plane can be written as:

$$
\begin{aligned}
C_{T} & =C_{f}+C_{1}+C_{2} \\
=C_{f}+\varepsilon_{r 1}^{\prime} C_{o} & +\left(\varepsilon_{r 2}^{\prime}-\varepsilon_{r 1}^{\prime}\right) C_{o} \exp (-d / M) \\
& =C_{f}+\varepsilon_{e f f}^{\prime} C_{o}
\end{aligned}
$$

where $\varepsilon_{\text {eff }}^{\prime}$ is the effective dielectric constant of finite layer MUT as:

$$
\varepsilon_{e f f}^{\prime}=\varepsilon_{r 1}^{\prime}+\left(\varepsilon_{r 2}^{\prime}-\varepsilon_{r 1}^{\prime}\right) \exp (-d / M)
$$

However, Equation (9) is only valid for $\varepsilon_{r 1}{ }^{\prime}>\varepsilon_{r 2}{ }^{\prime}$. For finite MUT with one layer thickness, $d$ is backed by a conducting metallic plate $\left(\varepsilon_{r 1}{ }^{\prime}<\varepsilon_{r 2}{ }^{\prime}\right)$, the effective dielectric constant, $\varepsilon_{e f f}{ }^{\prime}$ can be expressed as:

$$
\frac{1}{\varepsilon_{e f f}^{\prime}}=\frac{1}{\varepsilon_{r 1}^{\prime}}+\left(\frac{1}{\varepsilon_{r 2}^{\prime}}-\frac{1}{\varepsilon_{r 1}^{\prime}}\right) \exp (-d / M)
$$

Since the dielectric constant of the metallic plate is assumed to be infinite $\left(\varepsilon_{r 2}{ }^{\prime} \approx \infty\right)$, therefore, the $1 / \varepsilon_{r 2}{ }^{\prime}$ term in Equation (10) is neglected and subsequently yields

$$
\varepsilon_{r 1}=\varepsilon_{e f f}[1-\exp (-d / M)]
$$

In Ref. [35], Equation (11) was modified and expanded into Equation (15) by adding three unknown constants, $a_{1}, a_{2}$, and $a_{3}$ (to be determined) in which the values of the constants are implicitly represented the $e_{11}$ and $e_{22}$ errors.

\subsection{Probe Aperture Calibration}

The actual normalized admittance, $\widetilde{Y}_{B B^{\prime} \_M U T}$, was measured with the aperture of the probe placed on a two-layer media [26], in which the first layered medium was a thin sample to be tested with thickness, $h$ and the second layered medium was the conducting plate. The value of the $\widetilde{Y}_{B B^{\prime}-M U T}$ of the thin MUT is obtained after de-embedding using (13). The effective relative permittivity, $\varepsilon_{\text {eff }}$ of the MUT can be estimated as [15]:

$$
\varepsilon_{e f f}=\left(\frac{Y_{0}}{j \omega C}\right) \widetilde{Y}_{B B^{\prime}-M U T}-\frac{C_{f}}{C}
$$


where

$$
\widetilde{Y}_{B B^{\prime} \_M U T}=\widetilde{Y}_{A A^{\prime} \_M U T}\left(\frac{\widetilde{Y}_{B B^{\prime} \_A i r}}{\widetilde{Y}_{A A^{\prime} \_A i r}}\right)
$$

where $\widetilde{Y}_{A A^{\prime} \_ \text {Air }}$ is the measured normalized admittance for air at plane $\mathrm{AA}^{\prime}$, and $\widetilde{Y}_{B B^{\prime} \_ \text {Air }}$ is the simulated standard value of admittance for air at aperture probe (plane $\mathrm{BB}^{\prime}$ ) using the COMSOL simulator as shown in Figure 7. In the simulation, the conductor of the coaxial probe is assumed to be a perfect conductor. The relationship between $\Gamma_{A A^{\prime}}$ and $\widetilde{Y}_{A A^{\prime}}$ is given as:

$$
\widetilde{Y}_{A A^{\prime} \_M U T}=\frac{1-\Gamma_{A A^{\prime} \_M U T}}{1+\Gamma_{A A^{\prime} \_M U T}}
$$

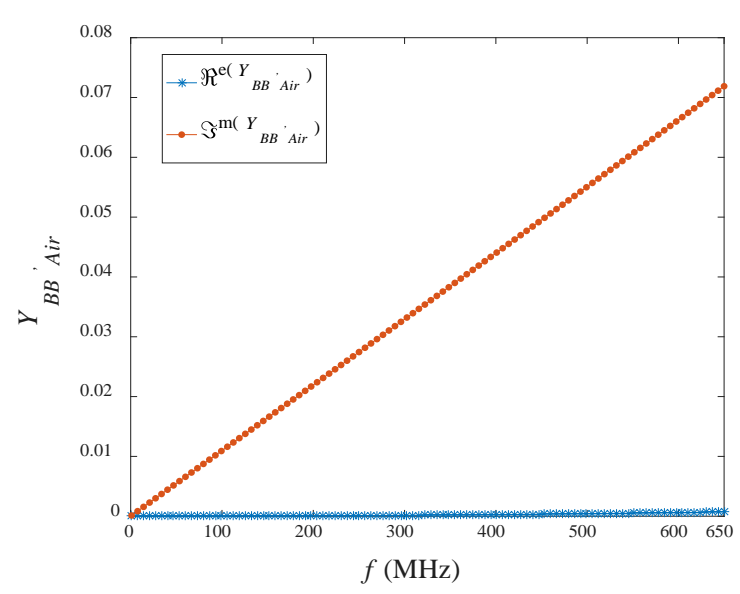

Figure 7. Simulated $\widetilde{Y}_{B B^{\prime} \_ \text {Air }}=\left[\Re \mathrm{e}\left(\widetilde{Y}_{B B^{\prime} \_A i r}\right)+j \mathfrak{J} m\left(\widetilde{Y}_{B B^{\prime} \_ \text {Air }}\right)\right]$ for air at aperture probe (plane $\left.\mathrm{BB}^{\prime}\right)$.

Symbol $Y_{o}=0.02 \mathrm{~S}, C=2.38 \varepsilon_{o}(b-a)[36], C_{f}=0.0107 \mathrm{pF}$ and $\omega$ are the characteristic admittance, aperture probe capacitance, fringing field capacitance, and the angular frequency, respectively.

\subsection{Effective Permittivity Calibration}

For thin solid planar material measurements, the scattering of the wave from probe's aperture would penetrate the thin planar material and impinge on the other layer-interface media. In this situation, the effective permittivity, $\varepsilon_{\text {eff }}$ of the thin specimen will be measured, but not the actual permittivity, $\varepsilon_{r}$ of the material [10]. In this study, the relationship between the actual relative permittivity, $\varepsilon_{r}$ and effective relative permittivity, $\varepsilon_{e f f}$ for a finite thickness planar specimen was empirically expressed as Ref. [35]:

$$
\varepsilon_{r}=\varepsilon_{e f f}\left(a_{1}+a_{2} e^{-h / M}+a_{3} e^{-2 h / M}\right)
$$

where $h$ is the thickness of the MUT. The empirical coefficient, $M$ was found to suite the large probe as described in Ref. [35], which can be roughly represented by single value as 0.006 . The unknown complex coefficients $\left(a_{1}, a_{2}\right.$, and $\left.a_{3}\right)$ values in Equation (15) were found by using three offset-short terminators $\left(\varepsilon_{r}=1\right)$, yielding the following:

$$
\begin{aligned}
& 1=\varepsilon_{e f f 1}\left(a_{1}+a_{2} e^{-h_{1} / M}+a_{3} e^{-2 h_{1} / M}\right) \\
& 1=\varepsilon_{e f f 2}\left(a_{1}+a_{2} e^{-h_{2} / M}+a_{3} e^{-2 h_{2} / M}\right) \\
& 1=\varepsilon_{e f f 3}\left(a_{1}+a_{2} e^{-h_{3} / M}+a_{3} e^{-2 h_{3} / M}\right)
\end{aligned}
$$


where $h_{1}, h_{2}$, and $h_{3}$ are the known lift-off distances between the aperture probe from the shorted plate. On the other hand, $\varepsilon_{\text {eff } 1}, \varepsilon_{\text {eff } 2}$, and $\varepsilon_{\text {eff } 3}$ are the corresponding effective permittivity of the three offset shorts, in which the values are obtained from (12). The unknown values of $a_{1}, a_{2}$, and $a_{3}$ in Equations (16)-(18) were explicitly determined using Cramer's rule as:

$$
\begin{gathered}
\left.a_{1}=\frac{\left\{\begin{array}{l}
\left(1 / \varepsilon_{e f f 1}\right)\left(e^{-\left(h_{2}+2 h_{3}\right) / M}-e^{-\left(2 h_{2}+h_{3}\right) / M}\right)-\left(1 / \varepsilon_{e f f 2}\right)\left(e^{-\left(h_{1}+2 h_{3}\right) / M}-e^{-\left(h_{3}+2 h_{1}\right) / M}\right) \\
+\left(1 / \varepsilon_{e f f 3}\right)\left(e^{-\left(h_{1}+2 h_{2}\right) / M}-e^{-\left(h_{2}+2 h_{1}\right) / M}\right)
\end{array}\right\}}{D}\right\} \\
\left.a_{2}=\frac{\left\{\begin{array}{l}
\left(1 / \varepsilon_{e f f 2}\right) e^{-2 h_{3} / M}-\left(1 / \varepsilon_{e f f 3}\right) e^{-2 h_{2} / M}-\left(1 / \varepsilon_{e f f 1}\right) e^{-2 h_{3} / M}+\left(1 / \varepsilon_{e f f 3}\right) e^{-2 h_{1} / M} \\
+\left(1 / \varepsilon_{e f f 1}\right) e^{-2 h_{2} / M}-\left(1 / \varepsilon_{e f f 2}\right) e^{-2 h_{1} / M}
\end{array}\right\}}{D}\right\} \\
a_{3}=\frac{\left\{\begin{array}{l}
\left(1 / \varepsilon_{e f f 3}\right) e^{-h_{2} / M}-\left(1 / \varepsilon_{e f f 2}\right) e^{-h_{3} / M}-\left(1 / \varepsilon_{e f f 3}\right) e^{-h_{1} / M}+\left(1 / \varepsilon_{e f f 1}\right) e^{-h_{3} / M} \\
+\left(1 / \varepsilon_{e f f 2}\right) e^{-h_{1} / M}-\left(1 / \varepsilon_{e f f 1}\right) e^{-h_{2} / M}
\end{array}\right.}{D}
\end{gathered}
$$

The determinant, $D$ of the Equations (19)-(21) are given as:

$$
D=\left\{e^{-\left(h_{2}+2 h_{3}\right) / M}-e^{-\left(2 h_{2}+h_{3}\right) / M}-e^{-\left(h_{1}+2 h_{3}\right) / M}+e^{-\left(h_{3}+2 h_{1}\right) / M}+e^{-\left(h_{1}+2 h_{2}\right) / M}-e^{-\left(h_{2}+2 h_{1}\right) / M}\right\}
$$

To perform offset-short measurements (Lift-off distances: $h_{1}, h_{2}$, and $h_{3}$ ), three cylindrical rings have been printed using 3D-printer with polylactic acid (PLA) material in which the ring centers are concave rounded with depth, $h_{1}=(1.0 \pm 0.1) \mathrm{mm}, h_{2}=(2.0 \pm 0.1) \mathrm{mm}$, and $h_{3}=(3.0 \pm 0.1) \mathrm{mm}$, respectively. It should be noted that the effective lift-off distance may be slightly shorter than the actual physical distance due to the strong coupling fringing field near to the probe aperture. The cylindrical rings backed by aluminum plate as shown in Figure 8, are used as calibration kits for this thin planar material measurements. As mentioned earlier, a large aperture probe has a strong and wide fringing field distribution compared to a small probe, thus non-metallic material such as polylactic acid (PLA) has been chosen to construct the cylindrical ring in order to reduce the field coupling effect from side wall in the area between aperture probe and aluminum plate.
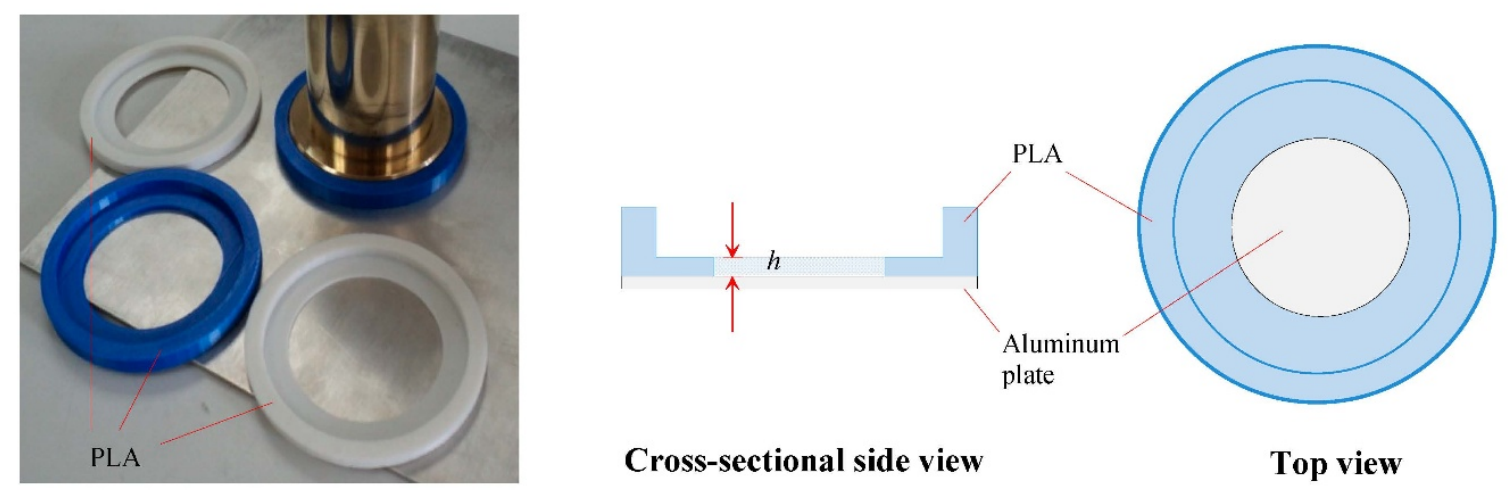

Figure 8. Printed offset short calibration kits.

\section{Results and Discussion}

\subsection{Reflection Coefficient, $\Gamma_{A A^{\prime}}$}

Figure $9 \mathrm{a}$, b shows the raw measured $\left|\Gamma_{A A^{\prime} \_M U T}\right|$ and $\varphi_{A A^{\prime} \_M U T}$ data of four thin low-loss MUTs obtained from network analyzer. The $\left|\Gamma_{A A^{\prime} \_} M U T\right|$ and $\varphi_{A A^{\prime} \_} M U T$ distinction between four MUTs are less significant when it is below $50 \mathrm{MHz}$, in which mainly caused by the size limitation of the coaxial probe. For instance, various coaxial probes (in Figure 10) are tested in order to observe and compare the measurement sensitivity towards the size of coaxial probe as listed in Tables 2 and 3. 


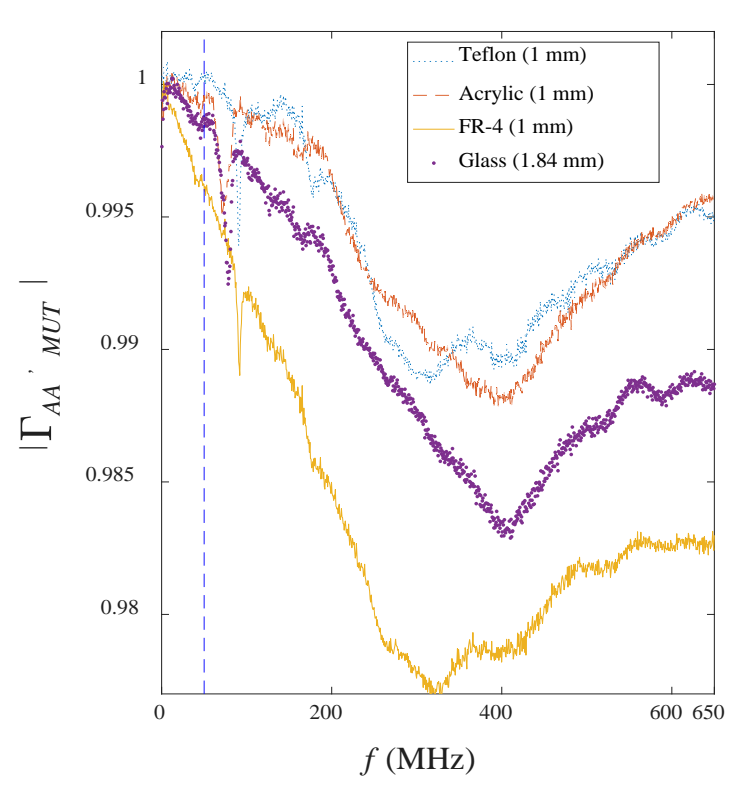

(a)

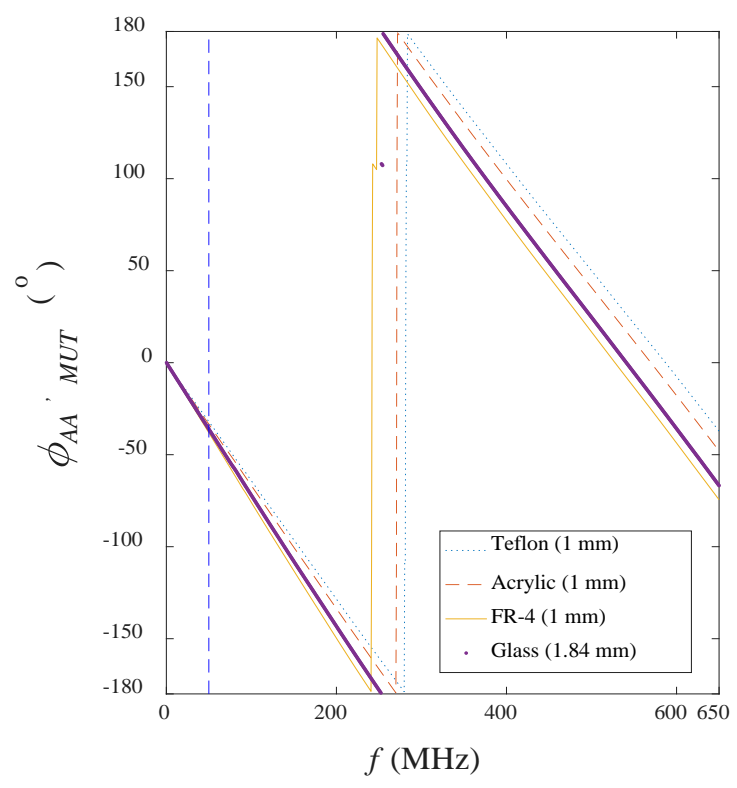

(b)

Figure 9. Variation in (a) measured $\left|\Gamma_{A A^{\prime} \_M U T}\right|$ and (b) measured $\varphi_{A A^{\prime} \_M U T}$ with frequency for the four materials under test (MUTs) at room temperature.

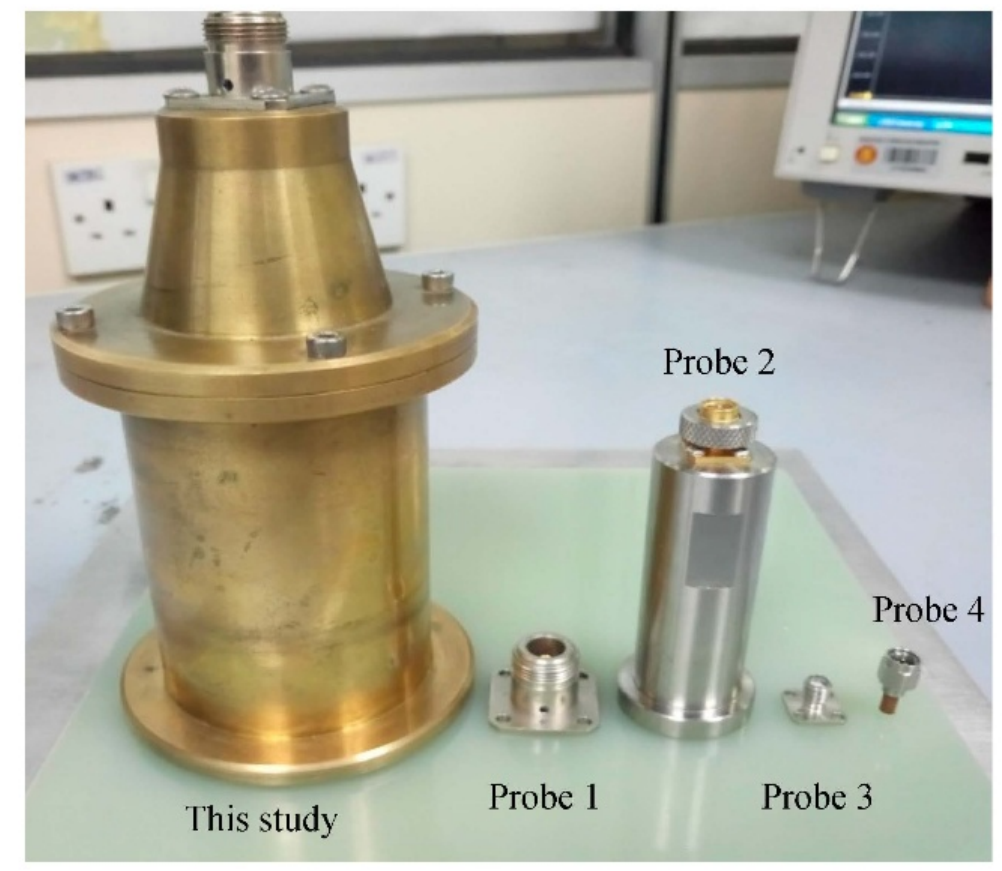

Figure 10. Various sizes of coaxial probe.

Up to five repeated reflection measurements (at different surface areas of the MUT) have been done for each MUT in which the average values and standard deviations for the measurement have been calculated. For this study probe, the linear magnitude differential, $\Delta\left|\Gamma_{A A^{\prime} \_M U T}\right|$ between the RF-4 $(h=1.0 \mathrm{~mm})$ and the Teflon $(h=1.0 \mathrm{~mm})$ is close to 0.004 in which is ten time greater to the existing resolution error (standard deviation: $10^{-4}$ ) as shown in Table 2 . On the other hand, the phase differential, $\triangle \varphi_{A A^{\prime} \_M U T}$ between FR-4 and Teflon at $50 \mathrm{MHz}$ is capable of achieving $6^{\circ}$ as illustrated in Table 3. Clearly, the larger the probe, the more stable and sensitive it can be achieved for reflection measurements at very low frequencies. 
Table 2. Measured $\left|\Gamma_{A A^{\prime}}\right|$ for Teflon and FR-4 sheets with thickness of $1 \mathrm{~mm}$ backed by metal plate at $50 \mathrm{MHz}$.

\begin{tabular}{|c|c|c|c|c|c|}
\hline \multirow{3}{*}{ Probe Size } & \multicolumn{4}{|c|}{$\left|\Gamma_{A A^{\prime} \_M U T}\right|$} & \multirow{2}{*}{$\begin{array}{c}\text { Differentiation of } \Delta\left|\Gamma_{A A^{\prime} \_M U T}\right| \\
\text { between Teflon and FR-4 }\end{array}$} \\
\hline & \multicolumn{2}{|c|}{ Teflon } & \multicolumn{2}{|c|}{ FR-4 } & \\
\hline & 1.000213 & Average: & 0.9954108 & Average: & \multirow{5}{*}{0.0041272} \\
\hline \multirow{4}{*}{$\begin{array}{l}\text { This study } \\
2 a=1.5 \mathrm{~cm} \\
2 b=4.8 \mathrm{~cm}\end{array}$} & 1.000345 & 1.0001019 & 0.9961075 & 0.9959747 & \\
\hline & 0.9999458 & Standard & 0.9957603 & Standard & \\
\hline & 0.9999258 & deviation: & 0.9964970 & deviation: & \\
\hline & 1.00008 & 0.0001784 & 0.9960977 & 0.0004091 & \\
\hline \multirow{5}{*}{$\begin{array}{c}\text { Probe } 1 \\
2 a=0.3 \mathrm{~cm} \\
2 b=1.0 \mathrm{~cm}\end{array}$} & 1.001418 & Average: & 1.000593 & Average: & \multirow{5}{*}{0.0008746} \\
\hline & 1.001521 & 1.001394 & 1.000355 & 1.0005194 & \\
\hline & 1.001302 & Standard & 1.000626 & Standard & \\
\hline & 1.001177 & deviation: & 1.000507 & deviation: & \\
\hline & 1.001552 & 0.000155902 & 1.000516 & 0.00010485 & \\
\hline \multirow{5}{*}{$\begin{array}{c}\text { Probe } 2 \\
2 a=0.24 \mathrm{~cm} \\
2 b=0.8 \mathrm{~cm}\end{array}$} & 0.9998745 & Average: & 0.9995621 & Average: & \multirow{5}{*}{0.0003735} \\
\hline & 1.000060 & 0.9998884 & 0.9994846 & 0.99951490 & \\
\hline & 0.9998878 & Standard & 0.9995518 & Standard & \\
\hline & 0.9999274 & deviation: & 0.9994819 & deviation: & \\
\hline & 0.9996925 & 0.000131850 & 0.9994941 & 0.000038824 & \\
\hline \multirow{5}{*}{$\begin{array}{c}\text { Probe } 3 \\
2 a=0.13 \mathrm{~cm} \\
2 b=0.42 \mathrm{~cm}\end{array}$} & 0.9996894 & Average: & 0.9995004 & Average: & \multirow{5}{*}{0.0000524} \\
\hline & 0.9996297 & 0.99972804 & 0.9995625 & 0.99967564 & \\
\hline & 0.9998415 & Standard & 0.9998173 & Standard & \\
\hline & 0.9997365 & deviation: & 0.9998234 & deviation: & \\
\hline & 0.9997431 & 0.000077999 & 0.9996746 & 0.00014613 & \\
\hline \multirow{5}{*}{$\begin{array}{c}\text { Probe } 4 \\
2 a=0.09 \mathrm{~cm} \\
2 b=0.3 \mathrm{~cm}\end{array}$} & 1.000269 & Average: & 1.000199 & Average: & \multirow{5}{*}{0.0000502} \\
\hline & 1.000183 & 1.000275 & 1.000161 & 1.0002248 & \\
\hline & 1.000358 & Standard & 1.000366 & Standard & \\
\hline & 1.000075 & deviation: & 1.000233 & deviation: & \\
\hline & 1.000490 & 0.000159385 & 1.000165 & 0.000084138 & \\
\hline
\end{tabular}

Table 3. Measured $\varphi_{A A^{\prime} \_M U T}$ for Teflon and FR-4 sheets with $h=1 \mathrm{~mm}$ backed by metal plate at $50 \mathrm{MHz}$.

\begin{tabular}{|c|c|c|c|c|c|}
\hline \multirow{2}{*}{ Probe Size } & \multicolumn{4}{|c|}{$\varphi_{A A^{\prime} \_M U T}\left(^{\circ}\right)$} & \multirow{2}{*}{$\begin{array}{c}\text { Differentiation of } \Delta \varphi_{A A^{\prime}} M U T \\
\text { between Teflon and FR-4 }\end{array}$} \\
\hline & \multicolumn{2}{|c|}{ Teflon } & \multicolumn{2}{|c|}{ FR-4 } & \\
\hline $\begin{array}{l}\text { This study } \\
2 a=1.5 \mathrm{~cm} \\
2 b=4.8 \mathrm{~cm}\end{array}$ & $\begin{array}{c}-32.3000 \\
-32.13884 \\
-32.25762 \\
-32.02661 \\
-32.3628 \\
\end{array}$ & $\begin{array}{c}\text { Average: } \\
-32.21717 \\
\text { Standard } \\
\text { deviation: } \\
0.134307\end{array}$ & $\begin{array}{l}-38.56207 \\
-38.64224 \\
-38.43801 \\
-37.46768 \\
-38.60646 \\
\end{array}$ & $\begin{array}{c}\text { Average: } \\
\text {-38.34329 } \\
\text { Standard } \\
\text { deviation: } \\
0.495519\end{array}$ & $6.12612^{\circ}$ \\
\hline $\begin{array}{c}\text { Probe } 1 \\
2 a=0.3 \mathrm{~cm} \\
2 b=1.0 \mathrm{~cm}\end{array}$ & $\begin{array}{l}-1.943045 \\
-1.930690 \\
-1.934963 \\
-1.939431 \\
-1.948521 \\
\end{array}$ & $\begin{array}{c}\text { Average: } \\
-1.93933 \\
\text { Standard } \\
\text { deviation: } \\
0.00692831\end{array}$ & $\begin{array}{l}-2.522396 \\
-2.554037 \\
-2.535734 \\
-2.542843 \\
-2.558213 \\
\end{array}$ & $\begin{array}{l}\text { Average: } \\
-2.542644 \\
\text { Standard } \\
\text { deviation: } \\
0.0144045\end{array}$ & $0.603314^{\circ}$ \\
\hline $\begin{array}{c}\text { Probe } 2 \\
2 a=0.24 \mathrm{~cm} \\
2 b=0.8 \mathrm{~cm}\end{array}$ & $\begin{array}{l}-13.88491 \\
-13.89140 \\
-13.86970 \\
-13.89475 \\
-13.88055\end{array}$ & $\begin{array}{c}\text { Average: } \\
-13.884262 \\
\text { Standard } \\
\text { deviation: } \\
0.0098386975\end{array}$ & $\begin{array}{l}-14.31968 \\
-14.31454 \\
-14.32456 \\
-14.31788 \\
-14.29945 \\
\end{array}$ & $\begin{array}{c}\text { Average: } \\
-14.315222 \\
\text { Standard } \\
\text { deviation: } \\
0.00953097686\end{array}$ & $0.43096^{\circ}$ \\
\hline $\begin{array}{c}\text { Probe } 3 \\
2 a=0.13 \mathrm{~cm} \\
2 b=0.42 \mathrm{~cm}\end{array}$ & $\begin{array}{l}-1.426506 \\
-1.417838 \\
-1.419884 \\
-1.418287 \\
-1.426802 \\
\end{array}$ & $\begin{array}{c}\text { Average: } \\
-1.4218634 \\
\text { Standard } \\
\text { deviation: } \\
0.00444004\end{array}$ & $\begin{array}{l}-1.589263 \\
-1.579990 \\
-1.588442 \\
-1.583723 \\
-1.585592 \\
\end{array}$ & $\begin{array}{c}\text { Average: } \\
-1.585402 \\
\text { Standard } \\
\text { deviation: } \\
0.00375146\end{array}$ & $0.163539^{\circ}$ \\
\hline $\begin{array}{c}\text { Probe } 4 \\
2 a=0.09 \mathrm{~cm} \\
2 b=0.3 \mathrm{~cm}\end{array}$ & $\begin{array}{l}-2.60528 \\
-2.60139 \\
-2.618748 \\
-2.623582 \\
-2.604237\end{array}$ & $\begin{array}{c}\text { Average: } \\
-2.6106474 \\
\text { Standard } \\
\text { deviation: } \\
0.00985552\end{array}$ & $\begin{array}{l}-2.71289 \\
-2.679226 \\
-2.694912 \\
-2.674806 \\
-2.679861\end{array}$ & $\begin{array}{c}\text { Average: } \\
\text {-2.688339 } \\
\text { Standard } \\
\text { deviation: } \\
0.01568456\end{array}$ & $0.077692^{\circ}$ \\
\hline
\end{tabular}




\subsection{Normalized Admittance, $\tilde{Y}_{B B^{\prime}}$}

Figure 11a,b shows the normalized admittance $\widetilde{Y}_{B B^{\prime} \_M U T}=\Re e\left(\widetilde{Y}_{B B^{\prime} \_M U T}\right)+j \mathfrak{\jmath} m\left(\widetilde{Y}_{B B^{\prime} \_M U T}\right)$ of the four MUTs converted based on the raw $\Gamma_{A A^{\prime}}$ MUT data using Equations (13) and (14). Typically, the lower the loss for the MUT, the lower the value for real part, $\Re e\left(\widetilde{Y}_{B B^{\prime} \_M U T}\right)$ (normalized conductance) as shown in Figure 11a. The case for the imaginary part, $\mathfrak{J} m\left(\widetilde{Y}_{B B_{-}^{\prime} M U T}\right)$ (normalized susceptance) indicates that the $\mathfrak{J} m\left(\widetilde{Y}_{B B^{\prime} \_} M U T\right)$ property is no longer linearly proportional to the operating frequency, $f$ over than $400 \mathrm{MHz}$ as shown in Figure $11 \mathrm{~b}$. Hence, the prediction of $\varepsilon_{r}$ value will be less accurate because the model (11) used in the conversion assumed the value of $\mathfrak{J} m\left(\widetilde{Y}_{B B^{\prime} \_M U T}\right)$ is proportional to the frequency.

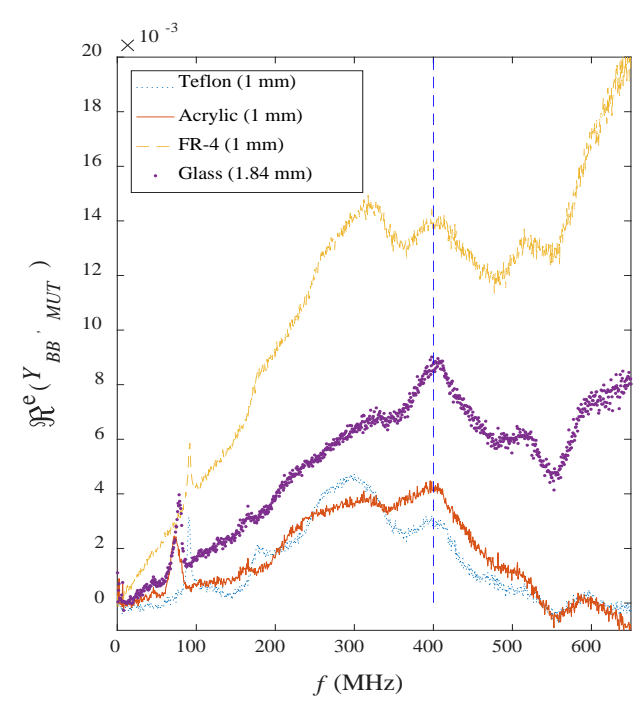

(a)

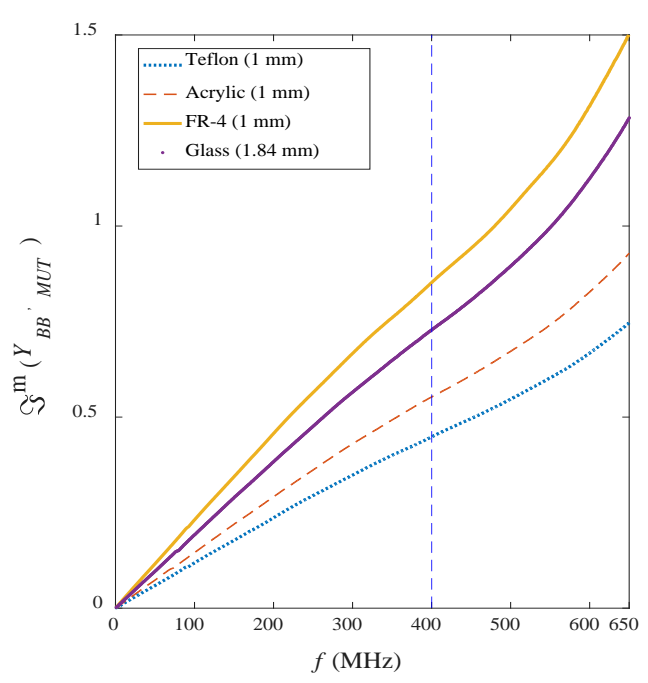

(b)

Figure 11. Comparison of (a) real part, $\Re e\left(\widetilde{Y}_{B B^{\prime} \_M U T}\right)$, and (b) imaginary part, $\mathfrak{\jmath} m\left(\widetilde{Y}_{B B^{\prime} \_M U T}\right)$, of the normalized admittance at probe aperture for four MUTs.

\subsection{Effective Permittivity, $\varepsilon_{\text {eff }}$}

Figure $12 \mathrm{a}, \mathrm{b}$ shows the effective relative permittivity, $\varepsilon_{\text {eff }}=\varepsilon_{\text {eff }}^{\prime}-j \varepsilon_{\text {eff }}$ " versus operating $^{\prime}$ frequency, $f$.

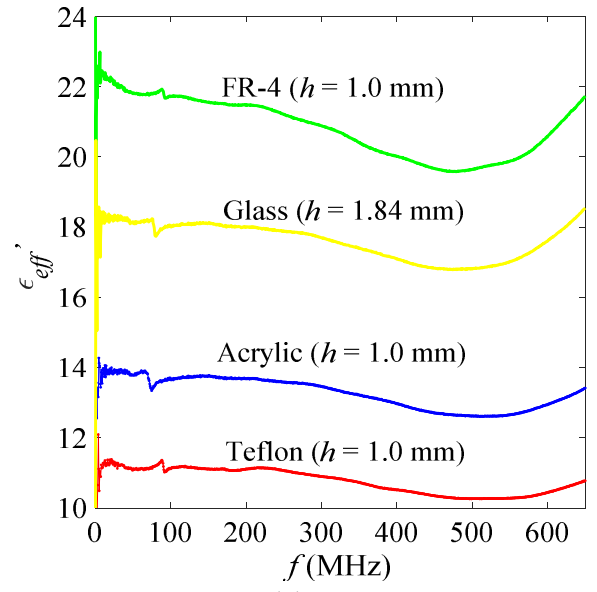

(a)

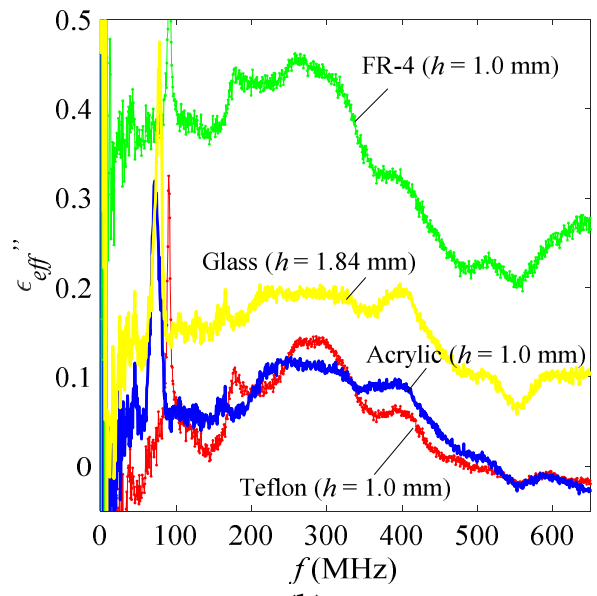

(b)

Figure 12. Comparison of (a) real part, $\varepsilon_{e f f}$ and (b) imaginary part, $\varepsilon_{e f f}{ }^{\prime \prime}$, of the effective relative permittivity, $\varepsilon_{e f f}$ for four MUTs. 
The value of $\varepsilon_{e f f}$ has been determined using Equation (12) and it is higher than the actual $\varepsilon_{r}$ value of the MUT in which the $\varepsilon_{\text {eff }}$ value is depended on the thickness, $h$ of the MUT backed by metal plate. This is caused by the thinness of MUT at coaxial probe aperture, whereby the scattering of the wave from probe aperture will penetrate the MUT and coupling with the metal plate, as well as reflected by the metal plate on other side of the MUT [37].

\subsection{Actual Relative Permittivity, $\varepsilon_{r}$}

Figure 13a,b shows the predicted $\varepsilon_{r}{ }^{\prime}$ and $\tan \delta=\varepsilon_{r}{ }^{\prime \prime} / \varepsilon_{r}{ }^{\prime}$ of four thin low-loss MUTs which are in good agreement with expected values as tabulated in Table 2. The scattered $\varepsilon_{r}{ }^{\prime}$ and $\tan \delta$ data in Figure 13a,b have been smoothed by Local Polynomial Regression (Loess) algorithm, which is available in built-in MATLAB "smooth" command. The smoothed data are represented by the black solid lines in Figure 13a,b. As expected, the coaxial probe is very difficult to provide high stability reflection measurement for the low-loss MUT at very low operating frequencies (refer to Figure 9). Hence, indirectly, the uncertainty of the predicted $\varepsilon_{r}{ }^{\prime}$ and $\tan \delta$ (especially for small values of $\tan \delta$ ) are increased when the operating frequency decreases to below $50 \mathrm{MHz}$.

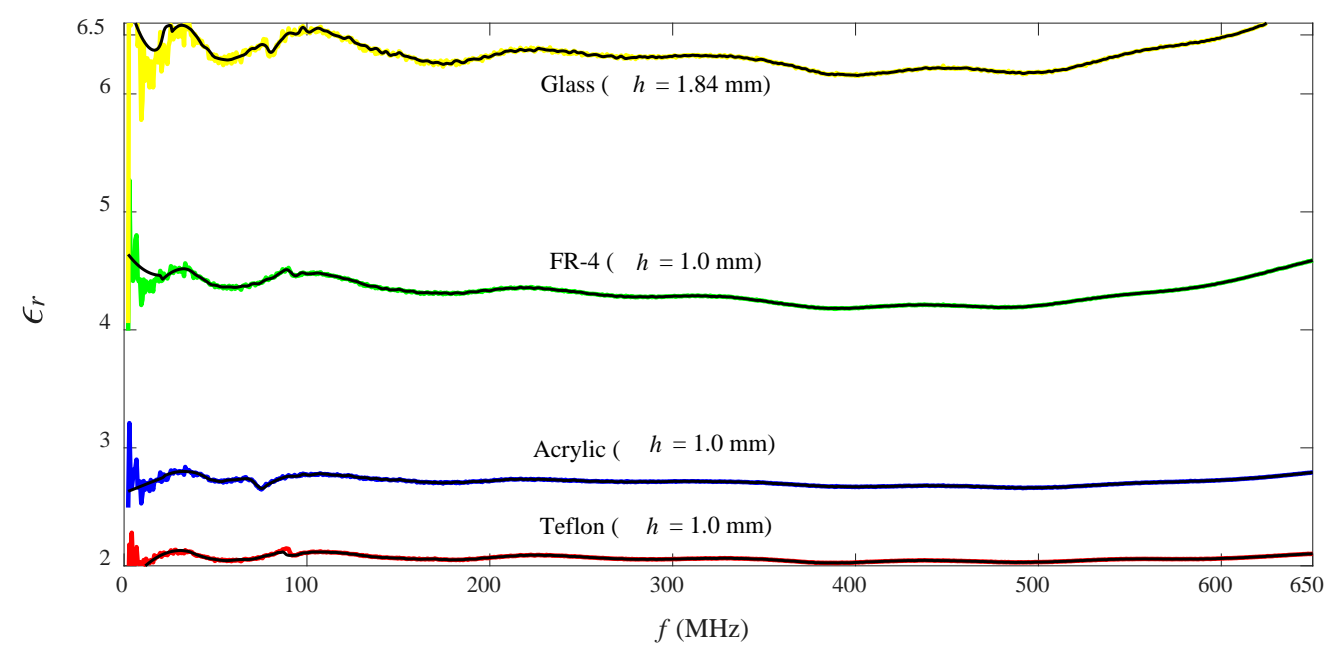

(a)

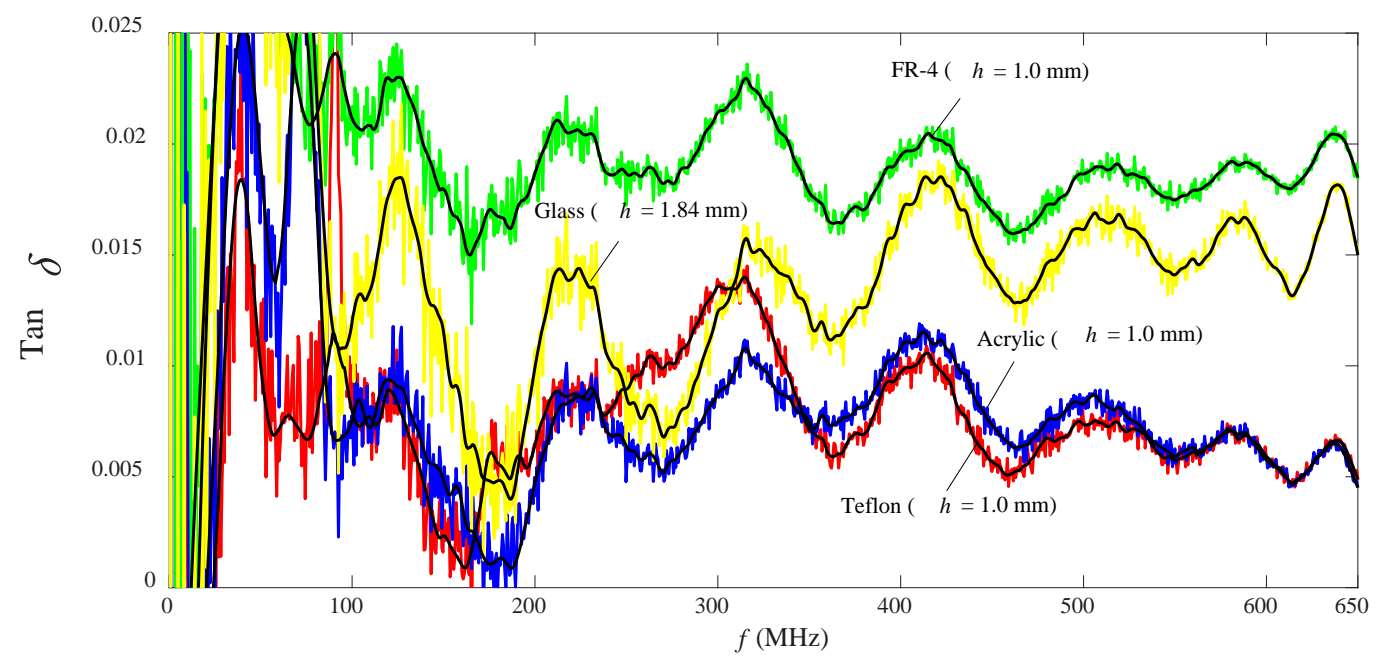

(b)

Figure 13. Variation in (a) predicted $\varepsilon_{r}{ }^{\prime}$ and (b) predicted $\tan \delta$ with frequency for the MUTs at room temperature. 
Figure 14 shows the percentage of the relative error between the smoothed values of $\varepsilon_{r}{ }^{\prime}$ in Figure 13a and the expected values of $\varepsilon_{r}{ }^{\prime}$ in Table 4. The percentage of the average relative errors, $\left|\Delta \varepsilon_{r}^{\prime} / \varepsilon_{r}^{\prime}\right|$ are less than $6 \%$ for overall measurements from $1 \mathrm{MHz}$ to $400 \mathrm{MHz}$.

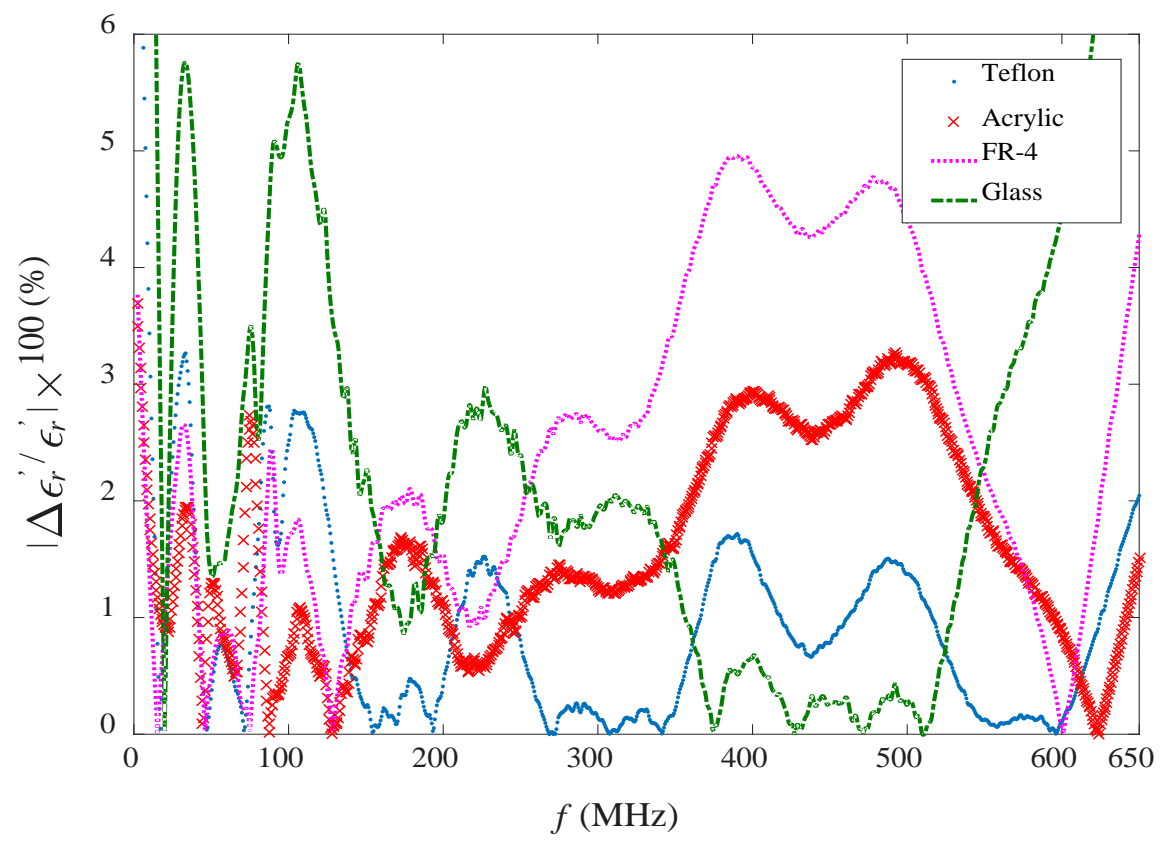

Figure 14. Variation in \% relative error of $\varepsilon_{r}{ }^{\prime}$.

Table 4. Expected values for $\varepsilon_{r}{ }^{\prime}$ and $\tan \delta$.

\begin{tabular}{ccc}
\hline MUT & $\varepsilon_{r}{ }^{\prime}$ (Typ) & $\tan \delta$ (Max) \\
\hline Teflon & 2.06 & 0.0004 \\
Acrylic & 2.75 & 0.019 \\
FR-4 & 4.4 & 0.022 \\
Glass & 6.1 & 0.0036 \\
\hline
\end{tabular}

\section{Conclusions}

One-port measurement using a large coaxial probe is an easy, durable, and cost-effective measurement method in large-scale material processing industries. In this study, the dielectric properties for thin low-loss materials (a few millimeter thickness) at very low frequencies (below $400 \mathrm{MHz}$ ) have been precisely measured using the open-ended coaxial probe techniques. This accuracy level of the measurement is rarely achieved by previous studies, which used the same technique for low-loss material at very low frequencies. In future, larger and longer sizes of coaxial probe may be re-designed in order to achieve good stability and higher sensitivity measurement below $50 \mathrm{MHz}$.

Author Contributions: Conceptualization, K.Y.Y.; Methodology, K.Y.Y.; Software, K.Y.Y.; Validation, M.S.S., and K.Y.Y.; Formal Analysis, K.Y.Y. and M.S.S.; Investigation, K.Y.Y. and M.S.S.; Resources, K.Y.Y.; Data Curation, K.Y.Y.; Writing_-Original Draft Preparation, K.Y.Y.; Writing-Review and Editing, K.Y.Y.; Visualization, K.Y.Y.; Supervision, K.Y.Y.; Project Administration, K.Y.Y.; Funding Acquisition, K.Y.Y.

Funding: This research was funded by i-Stone Technology and Research University Grant (GUP) from Universiti Teknologi Malaysia under project number Q.J130000.2523.15H30 and the Ministry of Higher Education of Malaysia (MOHE).

Acknowledgments: Authors would like to thank to Kok-San Chan, Shau-Lim Ooi, Tze-Lok Eng, Cha-Heng Toh for their invaluable support in probe fabrication.

Conflicts of Interest: The authors declare no conflict of interest. 


\section{References}

1. Bakhshiani, M.; Suster, M.A.; Mohseni, P. A Broadband Sensor Interface IC for Miniaturized Dielectric Spectroscopy from MHz to GHz. IEEE J. Solid-State Circuits 2014, 49, 1669-1681. [CrossRef]

2. Hegde, V.J.; Gallot-Lavallée, O.; Heux, L. Dielectric study of Polycaprolactone: A biodegradable polymer. In Proceedings of the 2016 IEEE International Conference on Dielectrics (ICD), Montpellier, France, 3-7 July 2016; Volume 1, pp. 293-296.

3. Noh, J.; Kim, S.M.; Heo, S.; Kang, S.C.; Kim, Y.; Lee, Y.G.; Park, H.; Lee, S.; Lee, B.H. Time Domain Reflectometry Analysis of the Dispersion of Metal-Insulator-Metal Capacitance. IEEE Electron Device Lett. 2017, 38, 521-524. [CrossRef]

4. Hewlett-Packard. User's Manual: HP 85070B Dielectric Probe Kit; Hewlett-Packard Company: Palo Alto, CA, USA, 1997.

5. Schmid \& Partner Engineering, AG. High Precision Dielectric Measurements: DAK; SPEAG: Zurich, Switzerland, 2018.

6. KEYCOM. Open Mode Probe Method Dielectric Constant and Dielectric Loss Tangent Measurement System; KEYCOM Characteristic Technologies: Tokyo, Japan, 2000.

7. APREL. Dielectric Probe Kit ALS-PR-DIEL; APREL Inc.: Kanata, ON, Canada, 2014.

8. Filali, B.; Boone, F.; Rhazi, J.; Ballivy, G. Design and Calibration of a Large Open-Ended Coaxial Probe for the Measurement of the Dielectric Properties of Concrete. IEEE Trans. Microw. Theory Tech. 2008, 56, 2322-2328. [CrossRef]

9. Otto, G.P.; Chew, W.C. Improved Calibration of a Large Open-Ended Coaxial Probe for Dielectric Measurements. IEEE Trans. Instrum. Meas. 1991, 40, 742-746. [CrossRef]

10. Damme, S.V.; Franchois, A.; Zutter, D.D.; Taerwe, L. Nondestructive Determination of the Steel Fiber Content in Concrete Slabs with an Open-Ended Coaxial Probe. IEEE Trans. Geosci. Remote Sens. 2004, 42, 2511-2521. [CrossRef]

11. Huang, Y. Design, Calibration and Data Interpretation for a One-Port Large Coaxial Dielectric Measurement Cell. Meas. Sci. Technol. 2001, 12, 111-115. [CrossRef]

12. Kitić, G.; Crnojević-Bengin, V. A Sensor for the Measurement of the Moisture of Undisturbed Soil Samples. Sensors 2013, 13, 1692-1705. [CrossRef]

13. Busssey, H. Dielectric Measurement in a Shielded Open Circuit Coaxial Line. IEEE Trans. Instrum. Meas. 1980, 29, 120-124. [CrossRef]

14. Brady, M.M.; Symons, S.A.; Stuchly, S.S. Dielectric Behavior of Selected Animal Tissues In Vitro at Frequencies from 2 to 4 GHz. IEEE Trans. Biomed. Eng. 1981, 28, 305-307. [CrossRef]

15. Atley, T.W.; Stuchly, M.A.; Stuchly, S.S. Measurement of Radio Frequency Permittivity of Biological Tissues with an Open-Ended Coaxial Line: Part I. IEEE Trans. Microw. Theory Tech. 1982, 30, 82-86. [CrossRef]

16. Gajda, G.; Stuchly, S.S. An Equivalent Circuit of an Open-Ended Coaxial Line. IEEE Trans. Instrum. Meas. 1983, 32, 506-508. [CrossRef]

17. Kraszewski, A.; Stuchly, S.S. Capacitance of Open-Ended Dielectric-Filled Coaxial Lines-Experimental Results. IEEE Trans. Instrum. Meas. 1983, 32, 517-519. [CrossRef]

18. Grant, J.P.; Clarke, R.N.; Symm, G.T.; Spyrou, N.M. A Critical Study of the Open-Ended Coaxial Line Sensor Technique for RF and Microwave Complex Permittivity Measurements. J. Phys. E 1989, 22, 757-770. [CrossRef]

19. Levine, H.; Papas, C.H. Theory of the Circular Diffraction Antenna. J.Appl. Phy. 1951, 22, 29-43. [CrossRef]

20. Nevels, R.D.; Butler, C.M.; Yablon, W. The Annular Slot Antenna in a Lossy Biological Medium. IEEE Trans. Microw. Theory Tech. 1985, 33, 314-319. [CrossRef]

21. Misra, D. A Quasi-Static Analysis of Open-Ended Coaxial Lines. IEEE Trans. Microw. Theory Techn. 1987, 35, 925-928. [CrossRef]

22. Anderson, L.S.; Gajda, G.B.; Stuchly, S.S. Analysis of an Open-Ended Coaxial Line Sensor in Layered Dielectric. IEEE Trans. Instrum. Meas. 1986, 35, 13-18. [CrossRef]

23. Fan, S.; Staebell, K.; Misra, D. Static Analysis of an Open-Ended Coaxial Line Terminated by Layered Media. IEEE Trans. Instrum. Meas. 1990, 39, 435-437. [CrossRef] 
24. Xu, Y.S.; Bosisio, R.G. Nondestructive Measurements of the Resistivity of Thin Conductive Films and the Dielectric Constant of Thin Substrates Using an Open-Ended Coaxial Line. IEE Proc. H Microw. Antennas Propag. 1992, 139, 500-506.

25. Li, L.L.; Ismail, N.H.; Taylor, L.S.; Davis, C.C. Flanged Coaxial Microwave Probes for Measuring Thin Moisture Layers. IEEE Trans. Biomed. Eng. 1992, 39, 49-57. [CrossRef]

26. Jiang, G.Q.; Wong, W.H.; Raskovich, E.Y.; Clark, W.G.; Hines, W.A.; Sanny, J. Measurement of the Microwave Dielectric Constant for Low-Loss Samples with Finite Thickness Using Open-Ended Coaxial-Line Probes. Rev. Sci. Instrum. 1993, 64, 1622-1626. [CrossRef]

27. Chen, G.; Li, K.; Ji, Z. Bilayered Dielectric Measurement with an Open-Ended Coaxial Probe. IEEE Trans. Microw. Theory Tech. 1994, 42, 966-971. [CrossRef]

28. Li, C.L.; Chen, K.M. Determination of Electromagnetic Properties of Materials Using Flanged Open-Ended Coaxial Probe-Full-Wave Analysis. IEEE Trans. Instrum. Meas. 1995, 44, 19-27. [CrossRef]

29. Ganchev, S.I.; Qaddoumi, N.; Bakhtiari, S.; Zoughi, R. Calibration and Measurement of Dielectric Properties of Finite Thickness Composite Sheets with Open-Ended Coaxial Sensors. IEEE Trans. Instrum. Meas. 1995, 44, 1023-1029. [CrossRef]

30. Lee, J.H.; Eom, H.J.; Jun, K.H. Reflection of a Coaxial Line Radiating into a Parallel Plate. IEEE Microw. Guid. Wave Lett. 1996, 6, 135-137. [CrossRef]

31. Folgero, K.; Tjomsland, T. Permittivity Measurement of Thin Liquid Layers Using Open Ended Coaxial Probes. Meas. Sci. Technol. 1996, 7, 1164-1173. [CrossRef]

32. Alanen, E.; Lahtinen, T.; Nuutinen, J. Variational Formulation of Open-Ended Coaxial Line in Contact with Layered Biological Medium. IEEE Trans. Biomed. Eng. 1998, 45, 1241-1248. [CrossRef] [PubMed]

33. Noh, Y.C.; Eom, H.J. Radiation from a Flanged Coaxial Line into a Dielectric Slab. IEEE Trans. Microw. Theory Techn. 1999, 47, 2158-2161. [CrossRef]

34. You, K.Y. RF Coaxial Slot Radiators: Modeling, Measurements, and Applications; Artech House: Norwood, MA, USA, 2015; pp. 19-56. ISBN 9781608078226.

35. You, K.Y.; Then, Y.L. Simple Calibration and Dielectric Measurement Technique for Thin Material Using Coaxial Probe. IEEE Sens. J. 2015, 15, 5393-5397. [CrossRef]

36. Gajda, G.B.; Stuchly, S.S. Numerical Analysis of Open-Ended Coaxial Lines. IEEE Trans. Microw. Theory Techn. 1983, 31, 380-384. [CrossRef]

37. Chen, L.F.; Ong, C.K.; Neo, C.P.; Varadan, V.V.; Varadan, V.K. Microwave Electronics: Measurement and Materials Characterization; John Wiley \& Sons, Ltd.: West Sussex, UK, 2004; ISBN 9780470844922. 